\title{
The effect of C1-esterase inhibitor on systemic inflammation in trauma patients with a femur fracture - The CAESAR study: study protocol for a randomized controlled trial
}

Marjolein Heeres ${ }^{1,3^{*}}$, Tjaakje Visser ${ }^{1}$, Karlijn JP van Wessem ${ }^{1}$, Anky HL Koenderman ${ }^{2}$, Paul FW Strengers ${ }^{2}$, Leo Koenderman ${ }^{3+}$ and Luke PH Leenen ${ }^{1+}$

\begin{abstract}
Background: Systemic inflammation in response to a femur fracture and the additional fixation is associated with inflammatory complications, such as acute respiratory distress syndrome and multiple organ dysfunction syndrome. The injury itself, but also the additional procedure of femoral fixation induces a release of pro-inflammatory cytokines such as interleukin-6. This results in an aggravation of the initial systemic inflammatory response, and can cause an increased risk for the development of inflammatory complications. Recent studies have shown that administration of the serum protein C1-esterase inhibitor can significantly reduce the release of circulating proinflammatory cytokines in response to acute systemic inflammation.
\end{abstract}

Objective: Attenuation of the surgery-induced additional systemic inflammatory response by perioperative treatment with C1-esterase inhibitor of trauma patients with a femur fracture.

Methods: The study is designed as a double-blind randomized placebo-controlled trial. Trauma patients with a femur fracture, Injury Severity Score $\geq 18$ and age 18-80 years are included after obtaining informed consent. They are randomized for administration of $200 \mathrm{U} / \mathrm{kg}$ C1-esterase inhibitor intravenously or placebo (saline $0.9 \%$ ) just before the start of the procedure of femoral fixation. The primary endpoint of the study is $\Delta$ interleukin- 6 , measured at $\mathrm{t}=0$, just before start of the femur fixation surgery and administration of C1-esterase inhibitor, and $t=6,6$ hours after administration of C1-esterase inhibitor and the femur fixation.

Conclusion: This study intents to identify C1-esterase inhibitor as a safe and potent anti-inflammatory agent, that is capable of suppressing systemic inflammation in trauma patients. This might facilitate early total care procedures by lowering the risk of inflammation in response to the surgical intervention. This could result in increased functional outcomes and reduced health care related costs.

Trial registration: clinicaltrials.gov NCT01275976 (January 12th 2011)

Keywords: ARDS, C1-esterase inhibitor, Complication, Femur, Fracture, Inflammation, Interleukin-6, Intramedullary fixation, MODS, Trauma

\footnotetext{
* Correspondence: M.Heeres-2@umcutrecht.nl

+ Contributed equally

'Department of Trauma Surgery, University Medical Centre Utrecht,

Heidelberglaan 100, 3508 GA, Utrecht, The Netherlands

Full list of author information is available at the end of the article
}

\section{Biomed Central}

(C) 2011 Heeres et al; licensee BioMed Central Ltd. This is an Open Access article distributed under the terms of the Creative Commons Attribution License (http://creativecommons.org/licenses/by/2.0), which permits unrestricted use, distribution, and reproduction in any medium, provided the original work is properly cited. 


\section{Background}

Trauma is a major cause of morbidity and mortality in people under the age of 50 years in the western world [1]. Death can occur as a direct result of the trauma induced injury, or as result of a dysfunctional immune response [2]. This excessive immune reaction is caused by the response to tissue injury, such as seen after trauma, surgery or burns. An overwhelming innate immune response is considered to be a major risk factor in the development of post-traumatic organ failure and sepsis. Additional injury, induced by surgical intervention, can increase the overall immune inflammatory reaction [3].

The lung is most often the first organ to be affected by an exaggerated systemic immune response, which can result in an acute respiratory distress syndrome (ARDS). This functional impairment can be followed by other organs, such as the liver, gastrointestinal tract and kidneys, leading to the so-called multiple organ dysfunction syndrome (MODS). Presence of ARDS and MODS is a major risk factor for mortality, long time morbidity, a prolonged hospital stay and high health care costs [4].

One of the early and systemically released cytokines in the early inflammatory response, is the pro-inflammatory cytokine interleukin-6 (IL-6). Therefore, this cytokine is widely used as an indicator for severity of the systemic inflammatory response in clinical studies [5]. Serum IL-6 levels have been demonstrated to be closely related to the magnitude of the injury (burden of trauma/first hit) and to the operative procedure (second hit) [6,7]. There is a correlation between the IL- 6 concentration and the underlying injury severity. Patients with a Injury Severity Score (ISS) $>18$ showed a more pronounced rise of IL-6 concentration compared to patients with a lower injury severity [8].

Femur fractures, have been found associated with a profound systemic inflammatory response [9-11]. Ideally, fractures should be managed without a clinically important delay to prevent excess blood loss, and preserve function. However, in case of femur fractures, internal fixation increases systemic inflammation [12]. In trauma patients with an already activated inflammatory response, this increase greatly enhances the risk of an excessive immune response [13,14]. To address this problem, the concept of damage control orthopedics (DCO) was developed $[15,16]$. This concept aims at minimizing the surgically induced inflammatory response through limiting surgical procedures $[16,17]$. However, DCO is a controversial approach, because limiting surgical procedures, can lead to a reduced quality of fracture healing, multiple interventions and a prolonged hospital stay. This places the treating surgeon with a difficult dilemma: early total care versus damage control [18-20].

Therefore, there is an unmet need for limiting/preventing the surgical induced inflammation, other than limiting or delaying surgery. Until now, there is a lack of pharmacological interventions that can reduce this surgery induced inflammation.

A promising intervention to attenuate the systemic innate immune response is the treatment with a high concentration of C1-esterase inhibitor (C1-INH) [21]. C1INH is an acute phase protein, produced by the liver in response to inflammatory conditions. C1-INH is a major inhibitor for both the complement and the contact system, and is, therefore, an important regulator of inflammatory reactions [22,23]. Apart from the modulation of the these systems, C1-INH has also been shown to attenuate systemic inflammation independently of the activation of complement [24]. In fact, Dorresteijn et al showed that administration of $\mathrm{C} 1-\mathrm{INH}$, in a 'human endotoxemia model', attenuates the release of pro-inflammatory cytokines, including IL-6, in healthy male volunteers [21]. This model evokes a systemic inflammatory response in the absence of complement activation [21,25].

\section{Aim of the study}

The aim of this study is to ascertain whether administration of C1-INH in trauma patients with a femur fracture can reduce the release of pro-inflammatory cytokines and, therefore, will contribute to attenuation of the inflammatory response, in response to a surgical intervention (second hit). This study can provide proof of principle for C1-INH as a potential drug for the prevention of late inflammatory complications in trauma patients.

\section{Methods \\ Objectives}

Attenuation of the surgery-induced additional systemic inflammatory response by perioperative treatment with C1-INH in trauma patients with a femur fracture. And the effect of C1-INH on clinical outcome (e.g. ARDS, MODS, mortality, length of hospital stay).

\section{Study design}

This clinical trial is a double blind, placebo-controlled, randomized study, investigating the anti-inflammatory effect of C1-INH on systemic inflammation induced by fixation of the femur fracture in trauma patients.

This study is conducted in accordance with the principles of the Declaration of Helsinki [26] and Good Clinical Practice Guidelines [27]. The independent ethics committee of the University Medical Centre Utrecht (UMCU) approved the study. Written informed consent will be obtained from all participating patients.

\section{Study population}

Seventy multi-trauma patients presented at the emergency department of the UMCU with an ISS $\geq 18$ and a femur 
fracture which need fixation, will be included in the study. Patients are eligible for the study if they meet all the inclusion and none of the exclusion criteria (Table 1).

\section{Randomization}

Subjects are randomly allocated to either the C1-INH group (intervention-group) or the placebo-group just before the start of the surgical repair of the femur fracture, using an 1:1 allocation ratio. Randomization will be performed by the distributing pharmacy (UMCU, The Netherlands) with the use of Design version 2.0 (Systat Software Inc., Chicago, IL, USA). The C1-INH and placebo solutions are prepared in identical non-transparent infusion bags, ensuring the double-blind fashion of the study. Patients, treating surgeons, investigators and nursing personnel involved in the study will be unaware of the randomization, and therefore, the solution applied.

\section{Study protocol}

When trauma patients meet the inclusion criteria, a first blood sample is taken within 12 hours after trauma. This blood sample serves as a reference for the degree of inflammation immediately after injury. Because the first blood sample needs to be drawn within 12 hours after trauma, it is possible that the first sample is drawn without the necessary informed consent and will be analyzed directly. This delayed informed consent may be required because the inflammatory response after the initial trauma is visible in the blood within the first 12 hours after trauma. Of course, the informed consent is obtained as soon as possible if the patient or his/her legal representative is able to. If no consent is obtained, the analyzed blood and the data will be destroyed and the patients will not receive $\mathrm{C} 1-\mathrm{INH}$ or placebo, because the randomization will only take place after informed consent is obtained.

Patients receive femur fixation surgery according to the current protocol in the UMCU. Just after induction of anesthesia a second blood sample will be drawn and after this withdrawal the subject receives either $\mathrm{C} 1-\mathrm{INH}$ in a dose of $200 \mathrm{U} / \mathrm{kg}$ body weight $(\mathrm{n}=35)$ or placebo (saline $0.9 \%, \mathrm{n}=35$ ) intravenously. Two hours and six hours after the skin incision for the surgical procedure for femoral fixation the next blood samples are taken.
The last samples are taken 24 and 48 hours and seven days after procedure of femoral fixation. An overview of the time frame of the study is shown in Figure 1.

\section{Outcome measurements}

The primary outcome will be the change in serum IL-6 concentration before and after surgical repair of a femur fracture in trauma patients in the presence or absence of C1-INH. We have chosen IL-6 as our primary endpoint because IL- 6 is one of the earliest released proinflammatory cytokines after trauma, which is detectable by multiplex assays. Several clinical studies have shown that IL- 6 is a good marker for the severity of inflammatory response $[5,8,10]$. Because not all patients are operated at the exact same time after trauma we will use the $\Delta$ IL-6 serum concentration (the difference in IL-6 level between $t=0$, at the start of the operation, and $t=6$, six hours after start of the operation) as our primary endpoint. This allows the detection of the difference between the systemic inflammation in patients treated with or without $\mathrm{C} 1-\mathrm{INH}$.

Secondary biochemical outcomes include the production of various pro- and anti-inflammatory cytokines, cellular activation markers and complement. Various hematological variables and clinical chemistry measurements, such as haemoglobin, haematocrit, leukocyte count, platelet count, $\mathrm{C}$-reactive protein and fibrinogen, are also determined. These values reflect the clinical condition of the patient and the severity of inflammation.

Secondary clinical outcomes include the effect of C1INH on the presence or absence of ARDS or MODS and appearance of SIRS, sepsis or septic shock. To evaluate the presence of these clinical conditions the Systemic Response Syndrome (SIRS)-score [28] and the Sequential Organ Failure Assessment (SOFA)-score [29] will be calculated on a daily base during hospitalization of the study subjects. The duration of admission at the intensive care unit, duration of mechanical ventilation and total days of hospital admission are all recorded.

\section{Sample size calculation}

The sample size calculation is based on damping of the increase in serum IL- 6 concentration by $30 \%$ in the C1INH group, compared to the placebo group [21,30,31].

Table 1 Patients in- and exclusion criteria

\begin{tabular}{ll}
\hline Inclusion criteria & Exclusion criteria \\
\hline Multi-trauma patient & Congenital C1-inhibitor deficiency \\
ISS* $^{*} 18$ & Use of immune suppressants \\
Femur fracture & Known hypersensitivity for blood \\
Age 18-80 years & Products \\
Informed consent & Pregnancy \\
& Fixation of the femoral fracture with external fixation or osteosynthesis \\
\hline
\end{tabular}




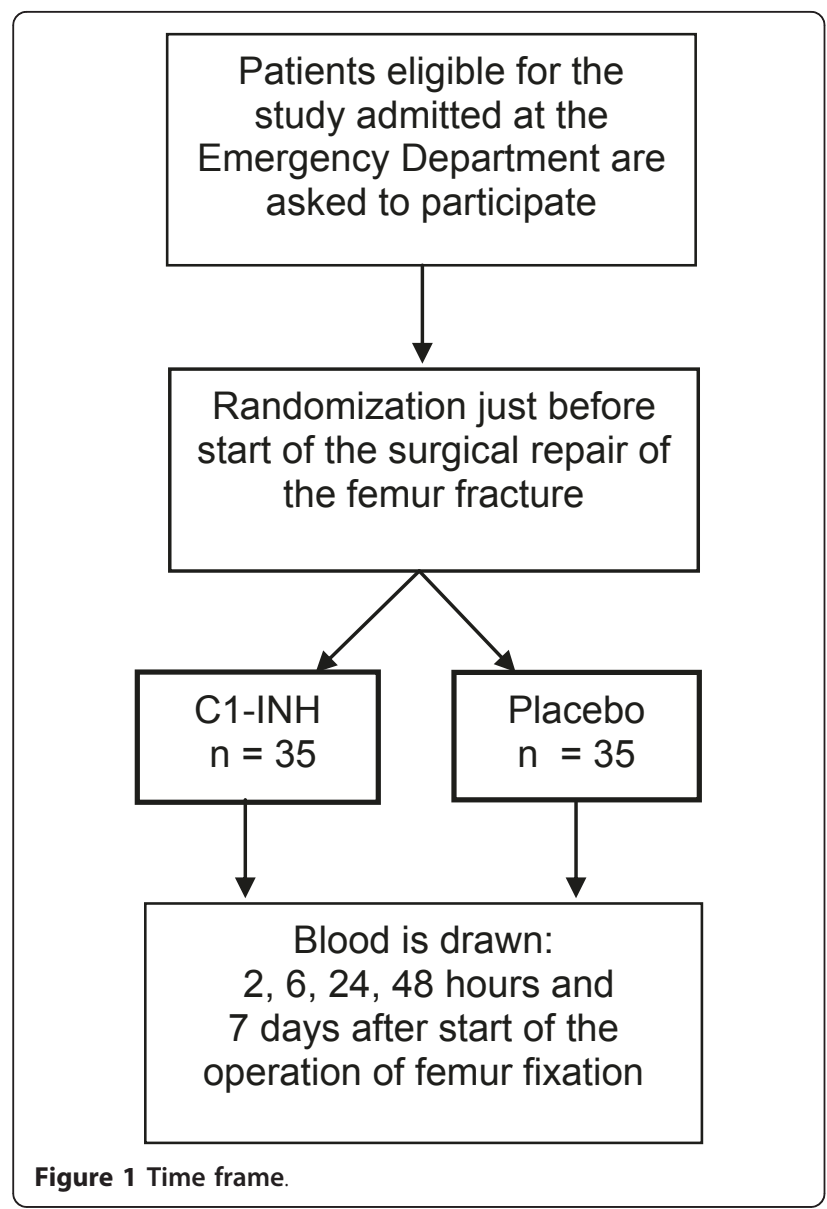

With an expected standard deviation of $50 \%[30,31]$ and a relevant decrease of IL-6 concentration of $30 \%$ [21,30,31], 35 patients in each sample-group (C1-INH or placebo) are needed to find a statistically significant difference (power 80\%, Type 1 error rate 0.05).

\section{Statistical analysis}

The primary endpoint, the $\Delta$ IL- 6 , will be determined with the use of a Students' $t$-test. The occurrence of inflammatory complications, such as MODS and ARDS, will be examined with the use of a survival analysis, such as Kaplan Meier or Cox proportional Hazard [32].

For comparisons, a $t$-test or Mann Whitney U-test will be used as appropriate.

Changes over time will be analyzed using repeated measurement analysis with time as within factor and treatment as between factor, using Analysis of Variance.

A $p$-value $<0.05$ is considered statistically significant.

The data will be analyzed using software programs SPSS version 17.0 (SPSS Inc., Chicago, IL, USA) and GraphPad Prism (GraphPad Software Inc., La Jolla, CA, USA).

\section{Interim analysis}

In this study there will be two analyses performed, one interim and the final analysis, using the O'Brien Fleming method [33]. The alpha used for the interim analysis will be 0.0054 , and for the final analysis the alpha used will be 0.0492 .

The interim analysis will be conducted by an independent Data Safety Monitoring Board (DSMB) after the inclusion of 35 succeeding patients, The DSMB is composed of three independent members, of which two clinicians and one statistician. After the interim analysis the DSMB is able to make recommendations. In case of clear benefit, harm or futility of the treatment, the DSMB might decide to end the study early.

\section{Discussion}

This study represents a novel therapeutic approach for the attenuation of the inflammatory response in trauma patients undergoing surgical intervention. To our knowledge this is the first randomized, placebo-controlled trial examining the effect of the acute-phase protein C1-INH on the suppression of the dysfunctional inflammatory reaction in trauma patients during fixation of their femur fracture. Our research, focusing on the potential therapeutic effect of C1-INH, could have important impact on outcome of patients after a severe trauma.

C1-INH is proven to be effective as treatment for improving the outcome in a variety of inflammatory disease models [22,24], including SIRS induced by infusion of LPS [21].

The dosage C1-INH of $200 \mathrm{U} / \mathrm{kg}$ bodyweight is distinct from earlier clinical studies. It is shown that C1-INH synthesis increases up to 2.5 times the normal rate during an acute phase response [34,35]. Various states of severe inflammation, such as found during sepsis, burns and ARDS, give a rise in the consumption of C1-INH [36]. Nuijens and colleagues also showed a reduction in functional C1-INH in patients with sepsis complicated by shock or ARDS [37]. Caliezi et al claimed that this decrease in C1-INH levels, as result of the consumption, is probably due to a relative deficiency in functional C1-INH as result of enzymatic cleavage in inflamed or ischemic tissue [22].

We also expect consumption of C1-INH in the severely injured trauma patients in our study and thus a relative deficiency in functional C1-INH. We hypothesize that this consumption is mainly due to (i) the trauma itself, (ii) the blood loss during trauma, (iii) the possible extra blood loss during operation, and (iv) the dilution of the blood compartment during resuscitation because of the use of e.g. saline infusion or packed cells (erythrocytes). To compensate this natural consumption of C1-INH in our patients, we will administer a dose of $200 \mathrm{U} / \mathrm{kg}$ 
bodyweight, approximately a dose of 14.000-16.000 U per patient. This dose is expected to increase the circulating C1-INH concentration at least as found under acute phase conditions [21].

C1-INH is found to be well tolerated up to a dose of 19.000 units in patients suffering from acute myocardial infarction [38]. In the study of Strüber et al a dose of $15.000 \mathrm{U}$, followed by $7.500 \mathrm{U}$ and $5.000 \mathrm{U}$ (total of 27.500 $\mathrm{U})$ was administered and tolerated without any side effects [39].

It is anticipated that this study will take three years to complete. The study is expected to start in October of 2011 and will end after the last blood sample is drawn from the seventieth successful included patient.

\section{Conclusion}

To the best of our knowledge this study is the first randomized controlled trial designed to assess the use of C1-INH as a possible drug for attenuation of the inflammatory response in trauma patients after a second hit.

And, if our hypothesis is proved correct, it will result in increased functional outcome in trauma patients and reduced health care related costs.

\section{Trial status}

Start trial October 2011, no patients included yet.

\begin{abstract}
Abbreviations
ARDS: Acute Respiratory Distress Syndrome; C1-INH: C1-esterase inhibitor; DCO: Damage Control Orthopedics; DSMB: Data Safety Monitoring Board; IL-6: Interleukin-6; ISS: Injury Severity Score; MODS: Multiple Organ Dysfunction Syndrome; SIRS: Systemic Inflammatory Response Syndrome; SOFA: Sequential Organ Failure Assessment; UMCU: University Medical Centre Utrecht
\end{abstract}

\section{Acknowledgements}

This trial is supported by a grant of Sanquin Blood Supply Foundation.

\section{Author details}

'Department of Trauma Surgery, University Medical Centre Utrecht, Heidelberglaan 100, 3508 GA, Utrecht, The Netherlands. ${ }^{2}$ Sanquin Blood Supply Foundation, Plesmanlaan 125, 1066 CX, Amsterdam, The Netherlands. ${ }^{3}$ Department of Respiratory Medicine, University Medical Centre Utrecht, Heidelberglaan 100, 3508 GA, Utrecht, The Netherlands.

\section{Authors' contributions}

$M H, T V$, LK and LPHL were involved in developing the original study design. $\mathrm{MH}$, LK and LPHL developed the research protocols. AHLK and PFWS developed the design for the study medication. KJPW and LPHL are responsible for the clinical input. MH, LK and LPHL drafted the paper. All authors provided input into revisions of the paper and have approved the final manuscript.

\section{Competing interests}

A. Koenderman and P. Strengers both work for Sanquin Blood Supply Foundation. The remaining authors declare to have no competing interests.

Received: 25 July 2011 Accepted: 11 October 2011

Published: 11 October 2011

\section{References}

1. Hietbrink F, Koenderman L, Rijkers G, Leenen L: Trauma: the role of the innate immune system. World J Emerg Surg 2006, 1:15.
2. Hietbrink F, Oudijk EJ, Braams R, Koenderman L, Leenen L: Aberrant regulation of polymorphonuclear phagocyte responsiveness in multitrauma patients. Shock 2006, 26(6):558-564.

3. Pillay J, Hietbrink F, Koenderman L, Leenen LP: The systemic inflammatory response induced by trauma is reflected by multiple phenotypes of blood neutrophils. Injury 2007, 38(12):1365-1372.

4. Ulvik A, Kvale R, Wentzel-Larsen T, Flaatten H: Multiple organ failure after trauma affects even long-term survival and functional status. Crit Care 2007, 11(5):R95.

5. Lenz A, Franklin GA, Cheadle WG: Systemic inflammation after trauma. Injury 2007, 38(12):1336-1345.

6. Cruickshank AM, Fraser WD, Burns HJ, Van Damme J, Shenkin A: Response of serum interleukin- 6 in patients undergoing elective surgery of varying severity. Clin Sci (Lond) 1990, 79(2):161-165.

7. Giannoudis PV, Smith RM, Bellamy MC, Morrison JF, Dickson RA, Guillou PJ: Stimulation of the inflammatory system by reamed and unreamed nailing of femoral fractures. An analysis of the second hit. J Bone Joint Surg Br 1999, 81(2):356-361.

8. Gebhard F, Pfetsch H, Steinbach G, Strecker W, Kinzl L, Bruckner UB: Is interleukin 6 an early marker of injury severity following major trauma in humans? Arch Surg 2000, 135(3):291-295.

9. Giannoudis PV, Harwood PJ, Loughenbury P, Van Griensven M, Krettek C, Pape HC: Correlation between IL- 6 levels and the systemic inflammatory response score: can an IL-6 cutoff predict a SIRS state? J Trauma 2008, 65(3):646-652

10. Kobbe P, Vodovotz Y, Kaczorowski DJ, Mollen KP, Billiar TR, Pape HC: Patterns of cytokine release and evolution of remote organ dysfunction after bilateral femur fracture. Shock 2008, 30(1):43-47.

11. Pape HC, Griensven MV, Hildebrand FF, Tzioupis CT, Sommer KL, Krettek CC, Giannoudis PV: Systemic inflammatory response after extremity or truncal fracture operations. J Trauma 2008, 65(6):1379-1384.

12. Morley JR, Smith RM, Pape HC, MacDonald DA, Trejdosiewitz LK, Giannoudis PV: Stimulation of the local femoral inflammatory response to fracture and intramedullary reaming: a preliminary study of the source of the second hit phenomenon. J Bone Joint Surg Br 2008, 90(3):393-399.

13. Pape HC, Van Griensven M, Rice J, Gansslen A, Hildebrand F, Zech S, Winny $M$, Lichtinghagen $\mathrm{R}$, Krettek $\mathrm{C}$ : Major secondary surgery in blunt trauma patients and perioperative cytokine liberation: determination of the clinical relevance of biochemical markers. J Trauma 2001, 50(6):989-1000.

14. Tschoeke SK, Hellmuth M, Hostmann A, Ertel W, Oberholzer A: The early second hit in trauma management augments the proinflammatory immune response to multiple injuries. J Trauma 2007, 62(6):1396-1403.

15. Pape $\mathrm{HC}$, Giannoudis $P$, Krettek $C$ : The timing of fracture treatment in polytrauma patients: relevance of damage control orthopedic surgery. Am J Surg 2002, 183(6):622-629.

16. Pape HC: Effects of changing strategies of fracture fixation on immunologic changes and systemic complications after multiple trauma: damage control orthopedic surgery. J Orthop Res 2008, 26(11):1478-1484.

17. Pape HC, Grimme K, Van Griensven M, Sott AH, Giannoudis P, Morley J, Roise O, Ellingsen E, Hildebrand F, Wiebe B, Krettek C: Impact of intramedullary instrumentation versus damage control for femoral fractures on immunoinflammatory parameters: prospective randomized analysis by the EPOFF Study Group. J Trauma 2003, 55(1):7-13.

18. Morshed S, Miclau T III, Bembom O, Cohen M, Knudson MM, Colford JM Jr: Delayed internal fixation of femoral shaft fracture reduces mortality among patients with multisystem trauma. J Bone Joint Surg Am 2009, 91(1):3-13.

19. Pape HC, Hildebrand F, Pertschy S, Zelle B, Garapati R, Grimme K, Krettek C, Reed RL: Changes in the management of femoral shaft fractures in polytrauma patients: from early total care to damage control orthopedic surgery. J Trauma 2002, 53(3):452-461.

20. Pape HC, Tsukamoto T, Kobbe P, Tarkin I, Katsoulis S, Peitzman A: Assessment of the clinical course with inflammatory parameters. Injury 2007, 38(12):1358-1364.

21. Dorresteijn MJ, Visser T, Cox LA, Bouw MP, Pillay J, Koenderman AH, Strengers PF, Leenen LP, van der Hoeven JG, Koenderman L, Pickkers P: C1esterase inhibitor attenuates the inflammatory response during human endotoxemia. Crit Care Med 2010, 38(11):2139-2145. 
22. Caliezi C, Wuillemin WA, Zeerleder S, Redondo M, Eisele B, Hack CE: C1Esterase inhibitor: an anti-inflammatory agent and its potential use in the treatment of diseases other than hereditary angioedema. Pharmacol Rev 2000, 52(1):91-112

23. Zeerleder S, Caliezi C, van Mierlo G, Eerenberg-Belmer A, Sulzer I, Hack CE, Wuillemin WA: Administration of $\mathrm{C} 1$ inhibitor reduces neutrophil activation in patients with sepsis. Clin Diagn Lab Immunol 2003, 10(4):529-535.

24. Liu D, Lu F, Qin G, Fernandes SM, Li J, Davis AE III: C1 inhibitor-mediated protection from sepsis. J Immunol 2007, 179(6):3966-3972.

25. Bahador M, Cross AS: From therapy to experimental model: a hundred years of endotoxin administration to human subjects. $J$ Endotoxin Res 2007, 13(5):251-279.

26. The Declaration of Helsinki. , (September 20th 2011) [http://www.wma. net/en/30publications/10policies/b3/].

27. The Good Clinical Practice Guidelines. , (September 20th 2011) [http:// www.ema.europa.eu/docs/en_GB/document_library/Scientific_guideline/ 2009/09/WC500002874.pdf].

28. Bone RC, Balk RA, Cerra FB, Dellinger RP, Fein AM, Knaus WA, Schein RM, Sibbald WJ: Definitions for sepsis and organ failure and guidelines for the use of innovative therapies in sepsis. The ACCP/SCCM Consensus Conference Committee. American College of Chest Physicians/Society of Critical Care Medicine. Chest 1992, 101(6):1644-1655.

29. Vincent $J$, de Mendonca A, Cantraine F, Moreno R, Takala J, Suter PM, Sprung CL, Colardyn F, Blecher S: Use of the SOFA score to assess the incidence of organ dysfunction/failure in intensive care units: results of a multicenter, prospective study. Working group on "sepsis-related problems" of the European Society of Intensive Care Medicine. Crit Care Med 1998, 26(11):1793-1800.

30. Maier B, Lefering R, Lehnert M, Laurer HL, Steudel WI, Neugebauer EA, Marzi I: Early versus late onset of multiple organ failure is associated with differing patterns of plasma cytokine biomarker expression and outcome after severe trauma. Shock 2007, 28(6):668-674.

31. Stensballe J, Christiansen M, Tonnesen E, Espersen K, Lippert FK, Rasmussen LS: The early IL-6 and IL-10 response in trauma is correlated with injury severity and mortality. Acta Anaesthesiol Scand 2009, 53(4):515-521.

32. Bull K, Spiegelhalter DJ: Survival analysis in observational studies. Stat Med 1997, 16(9):1041-1074.

33. O'Brien PC, Fleming TR: A multiple testing procedure for clinical trials. Biometrics 1979, 35(3):549-556.

34. Kirschfink $M$, Nurnberger W: $C 1$ inhibitor in anti-inflammatory therapy: from animal experiment to clinical application. Mol Immunol 1999, 36(45):225-232.

35. Wouters D, Wagenaar-Bos I, van Ham M, Zeerleder S: C1 inhibitor: just a serine protease inhibitor? New and old considerations on therapeutic applications of C1 inhibitor. Expert Opin Biol Ther 2008, 8(8):1225-1240.

36. Kirschfink M, Mollnes TE: C1-inhibitor: an anti-inflammatory reagent with therapeutic potential. Expert Opin Pharmacother 2001, 2(7):1073-1083.

37. Nuijens JH, Eerenberg-Belmer AJ, Huijbregts CC, Schreuder WO, FeltBersma RJ, Abbink JJ, Thijs LG, Hack CE: Proteolytic inactivation of plasma C1- inhibitor in sepsis. J Clin Invest 1989, 84(2):443-450.

38. de Zwaan C, Kleine AH, Diris JH, Glatz JF, Wellens HJ, Strengers PF, Tissing M, Hack CE, van Dieijen-Visser MP, Hermens WT: Continuous 48-h C1-inhibitor treatment, following reperfusion therapy, in patients with acute myocardial infarction. Eur Heart J 2002, 23(21):1670-1677.

39. Struber M, Hagl C, Hirt SW, Cremer J, Harringer W, Haverich A: C1-esterase inhibitor in graft failure after lung transplantation. Intensive Care Med 1999, 25(11):1315-1318.

doi:10.1186/1745-6215-12-223

Cite this article as: Heeres et al:: The effect of C1-esterase inhibitor on systemic inflammation in trauma patients with a femur fracture - The CAESAR study: study protocol for a randomized controlled trial. Trials 2011 12:223.

\section{Submit your next manuscript to BioMed Central and take full advantage of:}

- Convenient online submission

- Thorough peer review

- No space constraints or color figure charges

- Immediate publication on acceptance

- Inclusion in PubMed, CAS, Scopus and Google Scholar

- Research which is freely available for redistribution

Submit your manuscript at www.biomedcentral.com/submit
Biomed Central 